\title{
THE COMPOSITION OF HYDROGELS FOR CARTILAGE TISSUE ENGINEERING CAN INFLUENCE GLYCOSAMINOGLYCAN PROFILES
}

\author{
Q. G. Wang, N. Hughes, S. H. Cartmell, and N. J. Kuiper*
}

Institute for Science and Technology in Medicine, University of Keele, Huxley Building, Staffordshire, ST5 5BG, U.K.

\begin{abstract}
The injectable and hydrophilic nature of hydrogels makes them suitable candidates for cartilage tissue engineering. To date, a wide range of hydrogels have been proposed for articular cartilage regeneration but few studies have quantitatively compared chondrocyte behaviour and extracellular matrix (ECM) synthesis within the hydrogels. Herein we have examined the nature of ECM synthesis by chondrocytes seeded into four hydrogels formed by either temperature change, self-assembly or chemical crosslinking. Bovine articular cartilage chondrocytes were cultured for 14 days in Extracel®, Pluronic F127 blended with Type II collagen, Puramatrix ${ }^{\circledR}$ and Matrixhyal ${ }^{\circledR}$. The discriminatory and sensitive technique of fluorophoreassisted carbohydrate electrophoresis (FACE) was used to determine the fine detail of the glycosaminoglycans (GAG); hyaluronan and chondroitin sulphate. FACE analysis for chondroitin sulphate and hyaluronan profiles in Puramatrix ${ }^{\circledR}$ closely matched that of native cartilage. For each hydrogel, DNA content, viability and morphology were assessed. Total collagen and total sulphated GAG production were measured and normalised to DNA content. Significant differences were found in total collagen synthesis. By day 14, Extracel ${ }^{\circledR}$ and Puramatrix ${ }^{\circledR}$ had significantly more total collagen than Matrixhyal ${ }^{\circledR}$ $(1.77 \pm 0.26 \mu \mathrm{g}$ and $1.97 \pm 0.26 \mu \mathrm{g} v$ s. $0.60 \pm 0.26 \mu \mathrm{g} ; p<0.05)$. sGAG synthesis occurred in all hydrogels but a significantly higher amount of sGAG was retained within Extracel ${ }^{\circledR}$ at days 7 and $14(p<0.05)$. In summary, we have shown that the biochemical and biophysical characteristics of each hydrogel directly or indirectly influenced ECM formation. A detailed understanding of the ECM in the development of engineered constructs is an important step in monitoring the success of cartilage regeneration strategies.
\end{abstract}

Keywords: Glycosaminoglycans, cartilage tissue engineering, chondrocytes, hydrogels, hyaluronan, chondroitin sulphate, fluorophore-assisted carbohydrate electrophoresis.

\footnotetext{
*Address for correspondence:

Nikki Kuiper

School of Medicine (Keele campus)

Institute for Science \& Technology in Medicine,

University of Keele, Staffordshire, ST5 5BG

United Kingdom
}

Telephone Number: +44 01782733683

E-mail: n.j.kuiper@keele.ac.uk

\section{Introduction}

The injectable and hydrophilic nature of hydrogels makes them suitable candidates for cartilage tissue engineering (Zheng et al., 2009). Hydrogels can not only encapsulate cells but also maintain both cell viability and phenotype. Furthermore, they have the potential to support neocartilage formation (Passaretti et al., 2001, Saim et al., 2000). Hydrogels can be formed from or blended with cartilage extracellular matrix (ECM) components by methods such as temperature change, chemical crosslinking and self-assembly (Vinatier et al., 2006, Van Tomme et al., 2008). Several studies have examined chondrocyte behaviour in one type of hydrogel. Monroy et al. (2007) and Saim et al. (2000) examined chondrocyte behaviour in the temperature-sensitive gel, Pluronic F127. They demonstrated that Pluronic F127 could be successfully used to encapsulate chondrocytes and facilitate in vivo cartilage formation. More recent work by Lee and Park (2009) showed that Pluronic F127 could also be blended with ECM components to improve cell adhesion and ECM production. A major disadvantage to this method is that the ECM component can leach out of the hydrogel since it is not anchored to the Pluronic F127. One way to overcome this is to cross-link or chemically modify the ECM component or the surrounding hydrogel to reduce or prevent leaching. The ECM component, hyaluronan (HA), can be cross-linked or chemically modified in a variety of ways. For example, HA can be thiol-modified and bound to other ECM components without significantly reducing its activity (Prestwich, 2008). This approach has been used to develop novel hydrogels. One such hydrogel, Extracel $\AA$, can be formed by adding polyethylene glycol cross-linker to a mixture of thiol-modified HA and thiol-modified gelatin. Extracel ${ }^{\circledR}$ has not yet been used to culture chondrocytes. However it has been seeded with mesenchymal stem cells and implanted into rabbits where it has been found to form in vivo cartilage (Liu et al., 2006). All of the studies described herein illustrate the exciting potential of hydrogel but there is clearly a need for more definitive characterisation of the ECM produced within different hydrogel formulations.

Articular cartilage is composed of chondrocytes that organise the collagens, proteoglycans, glycosaminoglycans (GAGs) and non-collagenous proteins into a highly organised ECM (Buckwalter and Mankin, 1998). An ECM without GAGs would be drastically compromised since their biological functions include tissue hydration, resistance to compressive load, intracellular signalling, protein up-take, and cell migration (Prabhakar and Sasisekharan, 2006). GAGs are long 
chains of repeating disaccharides that are negatively charged and variably sulphated. With the exception of HA, GAGs are synthesised covalently bound to core proteins to form proteoglycans. In adult human and bovine cartilage, $50-80 \%$ of GAGs are chondroitin sulphate (CS) chains which comprise the repeating disaccharide unit; glucuronic acid and $\mathrm{N}$-acetylgalactosamine. Glucuronic acid monosaccharides are unsulphated. $\mathrm{N}$-acetylgalactosamine monosaccharides can be sulphated on carbon positions 4 (C4S or chondroitin-4 sulphated) and/or 6 (C6S or chondroitin-6 sulphated). HA accounts for $1-10 \%$ of GAGs in adult human and bovine articular cartilage. HA is composed of the repeating disaccharide unit; glucuronic acid and $\mathrm{N}$-acetylglucosamine. Neither monosaccharide is sulphated. Studies, including our own, have shown that as a function of development, age and disease the GAGs in adult human and bovine cartilage exhibit many changes in their chain length, composition and sulphation (Buckwalter et al., 1994, Plaas et al., 2001, Sharma et al., 2007, Bayliss et al., 2000, Bayliss et al., 1999, Lauder et al., 1998). All of the changes in CS and HA are thought to be initiated by the chondrocytes in response to their altered microenvironment. However the functional significance of these changes has yet to be elucidated.

To date, few studies have fully characterised the behaviour of chondrocytes seeded into hydrogels formed by different methods. Most studies report total ECM production rather than definitive molecular ECM information. This detailed information would improve our understanding of how the biochemical characteristics of a particular hydrogel impacts upon ECM formation. Mouw et al. (2005) employed more sophisticated methods to evaluate their engineered cartilage constructs to show how different biomaterials directly or indirectly influenced ECM production. In this study we have examined the nature of ECM synthesis by chondrocytes seeded into four different hydrogels formed by either temperature change, chemical cross-linking or self-assembly. We have assessed cell characteristics and metabolic activity. In addition, we have used the sensitive and discriminatory technique of fluorophore-assisted carbohydrate electrophoresis (FACE) to reveal differences in $\mathrm{CS}$ and HA fine structures.

\section{Materials and Methods}

\section{Isolation of bovine chondrocytes}

Full depth articular cartilage was dissected from the articulating surface of the trochleal humerus of four 18month-old cows. For each humerus, chondrocytes were isolated and seeded into the four hydrogel formulations. Chondrocyte isolation was performed as previously described (Wang et al., 2008). Briefly, diced cartilage was sequentially digested with $700 \mathrm{U} / \mathrm{ml}$ Pronase ETM (Sigma, St. Louis, MO, USA) for $1 \mathrm{~h}$, then $200 \mathrm{U} / \mathrm{ml}$ collagenase XI (Sigma) and $0.1 \mathrm{mg} / \mathrm{ml}$ DNase 1 (Sigma) for $16 \mathrm{~h}$. Chondrocytes from the supernatant were strained through a 70- $\mu \mathrm{m}$ cell sieve, washed in Complete Culture Medium (CCM), composed of Dulbecco's Modified Eagle's Medium supplemented with $10 \%(\mathrm{v} / \mathrm{v})$ foetal calf serum
(Invitrogen Gibco; www.invitrogen.com), $2.5 \mu \mathrm{g} / \mathrm{ml}$ Fungizone $^{\mathrm{TM}}$ (Sigma), $50 \mu \mathrm{g} / \mathrm{ml}$ gentamycin (Sigma) and $62 \mu \mathrm{g} / \mathrm{ml}$ ascorbic acid (Sigma) and centrifuged at $750 \mathrm{~g}$. The chondrocytes were washed three times before seeding directly into hydrogels.

\section{Hydrogel culture}

Freshly isolated bovine chondrocytes were seeded into 150 $\mu \mathrm{l}$ hydrogels at 4 million cells $/ \mathrm{ml}$. For each formulation, one hydrogel from each of the four isolations was cultured on transwell inserts (Becton Dickinson Labware, Oxford, U.K.; $10 \mathrm{~mm}$ inserts with $0.45 \mu \mathrm{m}$ pore size and pore density $1 \times 10^{8}$ pores $/ \mathrm{cm}^{2}$ ) in 24 well plates for $0,1,3,5,7$ or 14 days. During the culture period the CCM was replaced every third day. All spent culture media were stored at $-20^{\circ} \mathrm{C}$ for analysis. Four replicates of blank hydrogels (negative controls) were also prepared.

Each hydrogel formulation was prepared in accordance with the manufacturer's instructions. To prepare the Extracel ${ }^{\circledR}$ hydrogel (Glycosan Biosystems Inc., Salt Lake City, UT, USA), equal volumes of thiol-modified HA and thiol-modified gelatin were mixed with the chondrocytes. Cross-linker $(1 \% \mathrm{w} / \mathrm{v})$ was added to the HA and gelatin mixture at a final ratio of $1: 3$. Extracel ${ }^{\circledR}$ hydrogel was incubated at $37^{\circ} \mathrm{C}$ for 60 min to enable gelation and then 1 $\mathrm{ml}$ of CCM was added. The second hydrogel, Pluronic F127 (30\% w/v, Sigma), was mixed with bovine nasal cartilage Type II collagen $(20 \% \mathrm{w} / \mathrm{v}$, Sigma $)$ at $4{ }^{\circ} \mathrm{C}$ to form a Pluronic-Collagen blend. Chondrocytes were mixed directly with this blend and warmed to $37^{\circ} \mathrm{C}$ for $90 \mathrm{mins}$ to enable gelation. The third hydrogel, Puramatrix ${ }^{\circledR}(3 \mathrm{DM}$ Medical Technology Inc., Cambridge, MA, USA), is a peptide composed of 16 amino acid residues (Zhang et al., 1993). When exposed to physiological salt conditions the peptide forms a hydrogel, which can support ECM production (Yamaoka et al., 2006). To prepare the Puramatrix ${ }^{\circledR}$ hydrogel a stock (1\%) Puramatrix ${ }^{\circledR}$ was diluted in $20 \%(\mathrm{v} / \mathrm{v})$ sucrose solution to a concentration of $0.5 \%$. Chondrocytes were suspended in $10 \%(\mathrm{v} / \mathrm{v})$ sucrose solution and mixed with the diluted Puramatrix ${ }^{\circledR}$ to give a final concentration of $0.25 \%$. The Puramatrix ${ }^{\circledR}$ hydrogel was incubated at $37^{\circ} \mathrm{C}$ for $60 \mathrm{~min}$ to allow gelation and then $1 \mathrm{ml}$ of CCM was added. Matrixhyal ${ }^{\circledR}$, the fourth hydrogel used in the study, was a kind gift from Hyaltech Ltd (Edinburgh, U.K). This novel hydrogel comprised high molecular weight HA entrapped within a lightly crosslinked acetylated chitosan at neutral $\mathrm{pH}$ (Hyaltech Ltd). Matrixhyal ${ }^{\circledR}$ was directly mixed with the chondrocytes and then cultured at $37^{\circ} \mathrm{C}$ with $1 \mathrm{ml}$ of CCM.

\section{Cell viability}

Chondrocyte viability was assessed by Trypan blue exclusion before seeding into the hydrogels and with Live/ Dead Double Staining (BioChemika, Sigma) (Yoshida et al., 1998) after 0, 1, 3, 5, 7 and 14 days in culture. The Live/Dead stained viable cells green with calcein-AM and non-viable cells red with propidium iodide. The live/dead working solution was prepared by mixing $10 \mu \mathrm{l}$ of solution $\mathrm{A}$ (Calcein-AM) and $5 \mu \mathrm{l}$ of solution B (PI) solution with $5 \mathrm{ml}$ Phosphate Buffered Saline (PBS). Hydrogels were 
washed with PBS for 3 min first and then mixed with $1 \mathrm{ml}$ of assay solution and incubated at $37^{\circ} \mathrm{C}$ for 15 mins. The gel was placed on a glass slide and viewed under a fluorescence microscope. The fluorescence was detected with $490 \mathrm{~nm}$ excitation for simultaneous monitoring of viable and dead cells. With $545 \mathrm{~nm}$ excitation, only dead cells could be observed. Two hundred cells were counted in three separate regions of each hydrogel (4 replicates). The viability was assessed by dividing the number of viable cells to the total number of counted cells.

\section{Sample preparation for assays}

During the culture period, spent culture media were collected for analysis. The Extracel ${ }^{\circledR}$, Pluronic-Collagen and Puramatrix ${ }^{\circledR}$ hydrogels were disrupted mechanically by pipeting. The Matrixhyal ${ }^{\circledR}$ hydrogel was digested with $100 \mathrm{U} / \mathrm{ml}$ hyaluronidase (bovine testes, Sigma) for $6 \mathrm{hr}$ at $37^{\circ} \mathrm{C}$. Spent culture media or hydrogels were digested with $125 \mu \mathrm{g} / \mathrm{ml}$ Proteinase K (Sigma), in $100 \mathrm{mM}$ ammonium acetate, $\mathrm{pH} 7.0$ at $60^{\circ} \mathrm{C}$, for 4 hours. Blank hydrogels (negative controls) were prepared in the same manner.

\section{Assessment of cell number}

Cell number was assessed at 0, 1, 3, 5, 7 and 14 days by Picogreen ${ }^{\circledR}$ fluorescent DNA quantification (Molecular Probes, Eugene, OR, USA) as previously described (Wang et al., 2008). Fluorescence was read against a standard curve of calf thymus DNA (Sigma). The previously reported value of $7.7 \mathrm{pg}$ of DNA per chondrocyte was used to approximate cell number in the hydrogels (Kim et al., 1988).

\section{Determination of total collagen production}

Total collagen production was determined at 0, 5, 7 and 14 days using the hydroxyproline assay as described by Brown et al. (2001). Total collagen was not detectable until after 3 days in culture (unpublished observations). Standards $(0-10 \mu \mathrm{g} / \mathrm{ml})$ of hydroxyproline (Sigma) were prepared in distilled water. All reagents were procured from Sigma. Samples and standards were hydrolysed in $10 \mathrm{M}$ hydrochloric acid at $110^{\circ} \mathrm{C}$ for $16 \mathrm{~h}$. On cooling, the hydrolysates were partially neutralised with $1 \mathrm{M}$ sodium hydroxide. Aliquots $(50 \mu \mathrm{l})$ of each sample and each standard were added to a 96-well plate. Chloramine-T (100 $\mu \mathrm{l})$ and then Ehrlich's reagent $(100 \mu \mathrm{l})$ were added to each well. The plate was sealed and incubated for $45 \mathrm{mins}$ at $65^{\circ} \mathrm{C}$. Absorbance at $540 \mathrm{~nm}$ was read on a Labsystems Multiskan ${ }^{\circledR}$ Multisoft microplate reader (Labsystems, Helsinki, Finland). A multiplication factor of 7.2 was used to convert total hydroxyproline to total collagen (Cortivo et al., 1981).

\section{Determination of total sulphated glycosaminoglycan (sGAG) production}

Total sGAG production was determined at $0,1,3,5,7$ and 14 days using the 1,9-dimethylmethylene blue (DMMB) dye assay as described by Farndale et al. (1986). All reagents were obtained from Sigma. 4 X DMMB solution (32 mg DMMB, $1.52 \mathrm{~g}$ glycine, $1.19 \mathrm{~g} \mathrm{NaCl}, 47.5 \mathrm{ml}, 0.1$ $\mathrm{M} \mathrm{HCl}, \mathrm{pH} 3.0)$ was prepared. Standards $(0-200 \mu \mathrm{g} / \mathrm{ml})$ of bovine tracheal chondroitin sulphate (Sigma) were prepared in distilled water. Aliquots $(50 \mu \mathrm{l})$ of each sample and each standard were added to a 96-well plate. DMMB (200 $\mu \mathrm{l} /$ well) were added to all wells and the plate was immediately read at 530nm on a Wallac Multilabel Counter 1420 (Victor Wallac/Perkin Elmer, Waltham, MA, USA).

\section{Hyaluronan (HA) and chondroitin sulphate (CS) profiling by fluorophore-assisted carbohydrate electrophoresis (FACE)}

FACE was performed as previously described (Sharma et al., 2007; Wang et al., 2008) for Pluronic-Collagen, Puramatrix $\AA$ and Matrixhyal ${ }^{\circledR}$ but not for Extracel ${ }^{\circledR}$. The heavily thiol-modified HA component of Extracel ${ }^{\circledR}$ inhibited the activity of the GAG-specific enzymes (data not shown). GAGs were ethanol precipitated from Proteinase K digests from each hydrogel at day 14 . Aliquots from each hydrogel containing $>5 \mu \mathrm{g}$ sulphated GAG (as determined by the DMMB dye assay) were digested with GAG-specific enzymes (Seikagaku) in 100 $\mu \mathrm{l}$ of $50 \mathrm{mM}$ ammonium acetate buffer (Sigma). Briefly, HA was digested into disaccharides ( $\triangle \mathrm{DiHA}$ ) using 100 $\mathrm{mU} / \mathrm{ml}$ of hyaluronidase (Streptococcus dysgalactiae) for $1 \mathrm{~h}$ at $37^{\circ} \mathrm{C}$. CS was digested into disaccharides (chondroitin-6 sulphate, $\triangle \mathrm{Di}$ 6S; chondroitin-4 sulphate, $\triangle \mathrm{Di} 4 \mathrm{~S}$; unsulphated chondroitin, $\triangle \mathrm{Di} 0 \mathrm{~S}$ ) with $100 \mathrm{mU} /$ $\mathrm{ml}$ of chondroitinase $\mathrm{ABC}(\mathrm{cABC})$ for $3 \mathrm{~h}$ at $37^{\circ} \mathrm{C}$. Sulphation of CS was confirmed by incubation of $\mathrm{CABC}$ digested samples with $100 \mathrm{mU} / \mathrm{mL}$ of chondroitin-4ase and/or chondroitin-6ase for $12 \mathrm{~h}$ at $37^{\circ} \mathrm{C}$. After digestion, buffer was evaporated and digestion products were fluorescently tagged for $16 \mathrm{~h}$ at $37^{\circ} \mathrm{C}$ with $15 \mu \mathrm{l}$ of $0.1 \mathrm{M}$ 2-aminoacridone (Sigma) and reduced with 1.0M sodium cyanoborohydride (Sigma). After fluorotagging, $10 \mu \mathrm{l}$ of $25 \%$ glycerol were used to quench excess sodium cyanoborohydride.

All reagents for electrophoresis were purchased from Sigma. Samples and standards were run on a $0.75 \mathrm{M}$ Tris$0.5 \mathrm{M}$ Borate $\mathrm{pH} 7.0$ resolving gel $(10 \mathrm{~cm} \times 10 \mathrm{~cm} \times 0.5$ $\mathrm{cm}$ ) with $150 \mathrm{mM}$ Tris-Borate $\mathrm{pH} 8.8$ running buffer for $80 \mathrm{~min}$ at $4^{\circ} \mathrm{C}$. Gels were placed on a transilluminator light box fitted with a 312-nm light source. Fluorescent images were captured using a High CCD Camera (UVP, Cambridge, U.K.) and the mean pixel density for each product band was quantified using LAB WORKS Software. For each gel, FACE product bands were identified by their co-electrophoresis with a range of predefined fluorotagged saccharide standards (25-250 pmol). For comparison, native bovine articular cartilage $(250 \mu \mathrm{g}$ wet weight) obtained from the humerus was also analysed by FACE.

\section{Statistical analysis}

For each hydrogel, a sample size of four was used. Data are expressed as mean \pm standard error of the mean (SEM). Statistical analysis was carried out using a 2-way ANOVA with type of hydrogel and days in culture as independent variables and cell number, GAG and collagen production as dependent variables. Cell number, GAG and collagen production were compared between the four gel types at 

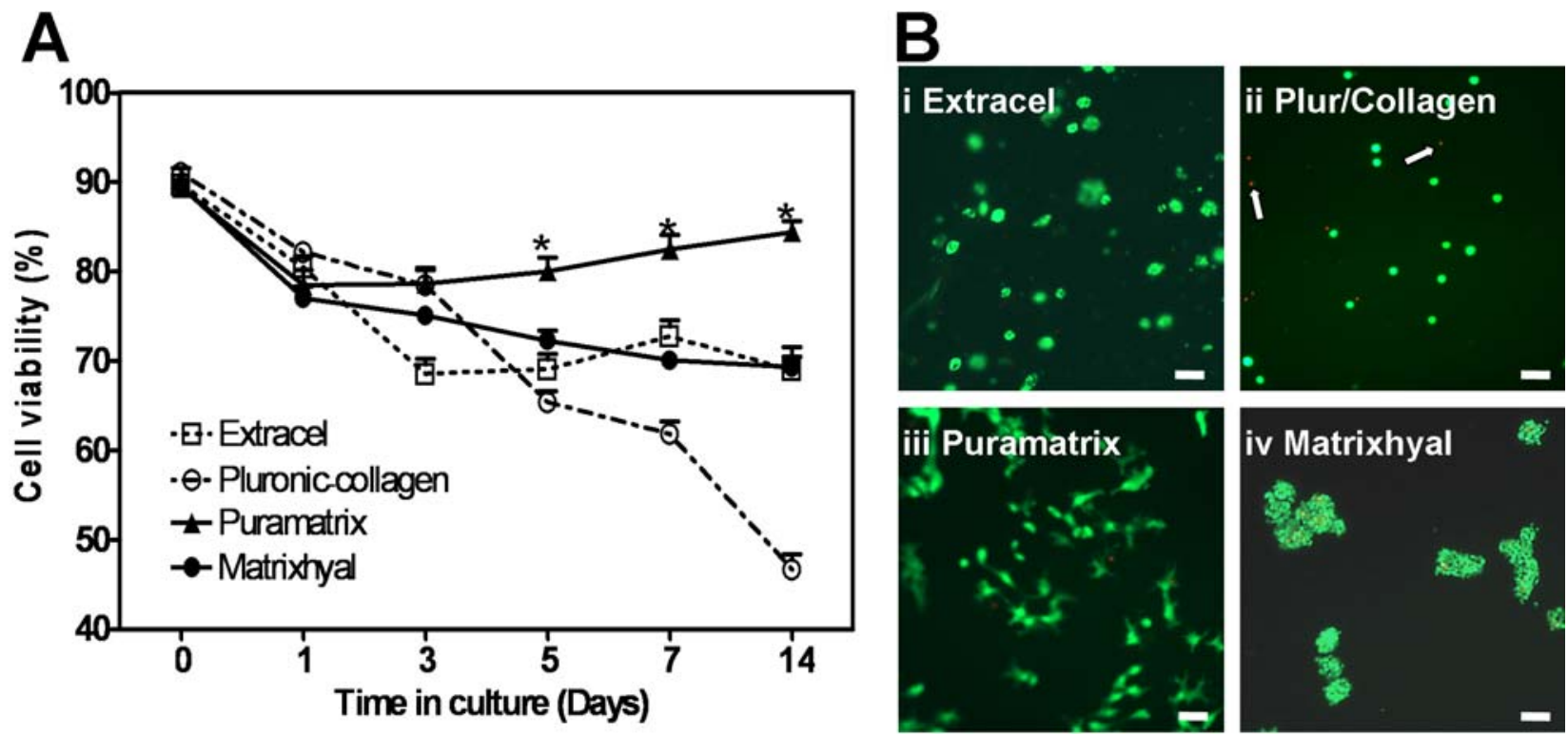

Fig.1 (A) Chondrocyte viability as assessed by Live/Dead Double Staining. Live cells stained green and dead cells stained red. Two hundred cells were counted in three separate regions of each hydrogel (4 replicates). These data are expressed as a percentage. (B) Representative interior of hydrogel stained with fluorescent Live/Dead Double Staining at day 14 day. The red fluorescence and arrow indicate the locations of cell nuclei. Bars $=100 \mu \mathrm{m}$. Asterisks indicate significant $\left({ }^{*} p<0.05\right)$ increase in cell number $v s$. all other hydrogels at the same time point.

two specific time points ( 7 and 14 days) with $\mathrm{p}$ values derived from the full ANOVA model. $P$ values $<0.05$ were considered significant. The Benjamin-Liu step down procedure was used to adjust for multiple comparisons (Benjamini and Liu, 1999).

\section{Results}

\section{Cell viability and number}

Prior to seeding, chondrocytes had good viability (>95\%) as assessed by Trypan blue exclusion. Cell viability as assessed by Live/Dead Double Staining (Fig. 1A), morphology (Fig. 1B) and number (Fig. 2) for the encapsulated chondrocytes varied depending upon their ECM microenvironment. In general, manipulation of chondrocytes during seeding into each hydrogel had a slightly negative effect upon their viability, which decreased from $95 \%$ to $90 \%$. Cell viability within Puramatrix ${ }^{\circledR}$ initially decreased between day 0 and day 1 but then steadily increased thereafter. At day 14, cells cultured in Puramatrix ${ }^{\circledR}$ appeared to be well spread and were uniformly distributed (Fig. 1Biii). During the 14-day experiment, cell number increased two-fold $\left(^{*} p<0.05\right.$, Fig. 2iii). During the 14-day culture period, cell viability in both Matrixhyal ${ }^{\circledR}$ and Extracel ${ }^{\circledR}$ decreased by $20 \%$. At day 14 , cells cultured in Extracel ${ }^{\circledR}$ displayed predominantly a rounded morphology and were uniformly distributed in clusters (Fig. 1Bi). Cell number remained constant throughout the time course (Fig.2i). By contrast, cells cultured in Matrixhyal ${ }^{\circledR}$ were more randomly distributed and appeared to be clustered in larger islands (Fig. 1Biv). Cell number increased three-fold during the time course $(* * p<0.001$, Fig. 2 iv $)$ however cell viability was determined to be at least $70 \%$ by day 14 . Although cells in Pluronic-Collagen were uniformly distributed and appeared rounded in their morphology (Fig. 1Bii) less than $50 \%$ were viable at the end of the 14 day culture period.

\section{Total collagen production}

For each time point we present total accumulated collagen content (Fig. 3A) and total accumulated collagen content normalised to total DNA content (Fig. 3B). Puramatrix ${ }^{\circledR}$ accumulated the most collagen of the four hydrogel formulations over the 14 day culture period (Fig. 3Aiii, ${ }^{*} p<0.05$ for days in culture). Collagen/DNA increased significantly in all four hydrogels from initial seeding to day 14 (Fig. $3 \mathrm{~B}, * p<0.05$ for days in culture). At day 7 no significant differences in collagen/DNA were found between the four hydrogels, but at day 14 Extracel ${ }^{\circledR}$ and Puramatrix ${ }^{\circledR}$ had significantly more collagen/DNA than Matrixhyal ${ }^{\circledR}(1.77 \pm 0.26 \mu \mathrm{g} / \mathrm{DNA}$ and $1.97 \pm 0.26 \mu \mathrm{g} / \mathrm{DNA}$ vs. $0.60 \pm 0.26 \mu \mathrm{g} / \mathrm{DNA} ; * * p<0.001)$.

\section{Total sulphated GAG production}

Fig. 4 illustrates the total amount of GAG accumulated and released into the surrounding media. For each time point we present total accumulated GAG content (Fig. 4A) and total accumulated GAG content normalised to total DNA content (Fig. 4B). All of the hydrogels accumulated sulphated GAG over the 14 day culture period. Matrixhyal ${ }^{\circledR}$ accumulated the most GAG of the four hydrogel formulations over the 14 day culture period but it also lost the most GAG to the surrounding media (Fig. $4 \mathrm{Biv}, p<0.05$ for days in culture). At day 7 and day 14, Extracel ${ }^{\circledR}$ had significantly more GAG/DNA than the other 


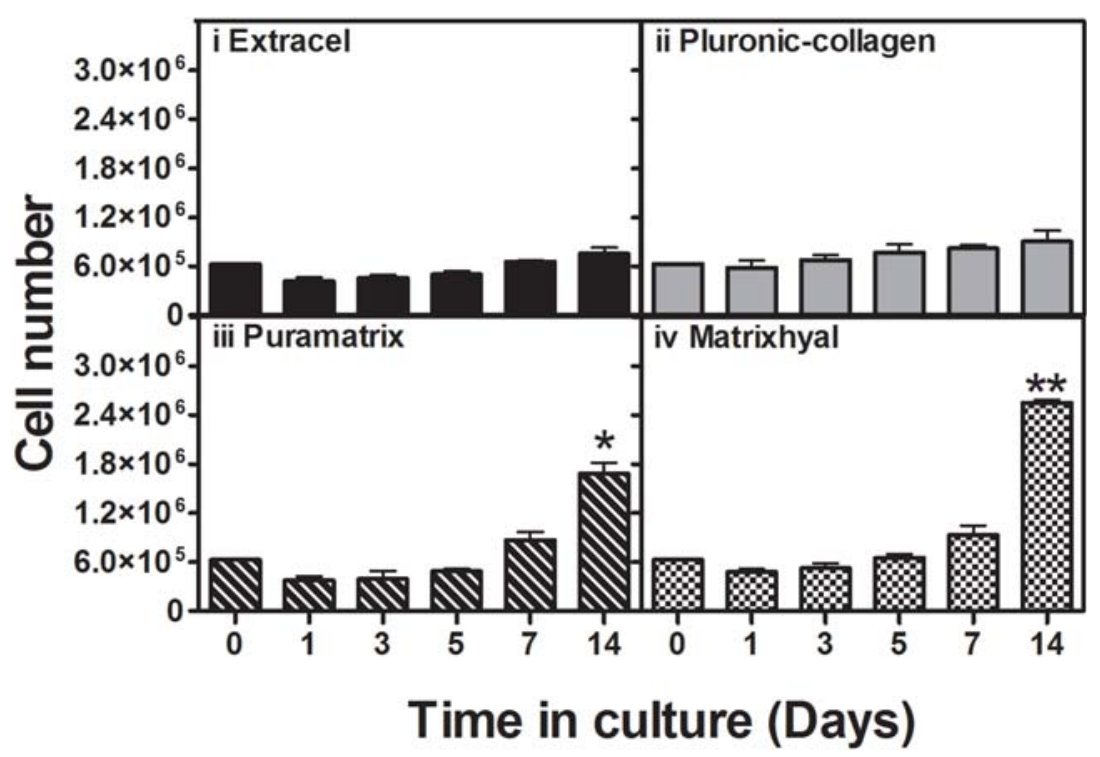

Fig.2 Chondrocyte cell number as assessed by Picogreen ${ }^{\circledR}$ dye. Cells were cultured in each hydrogel for two weeks. The initial seeding density was 600,000 cells per $150 \mu 1$ hydrogel (4 replicates). Asterisks indicate significant $(* p<0.05, * * p<0.001)$ increases in cell number $v s$. all other hydrogels at the same time point.
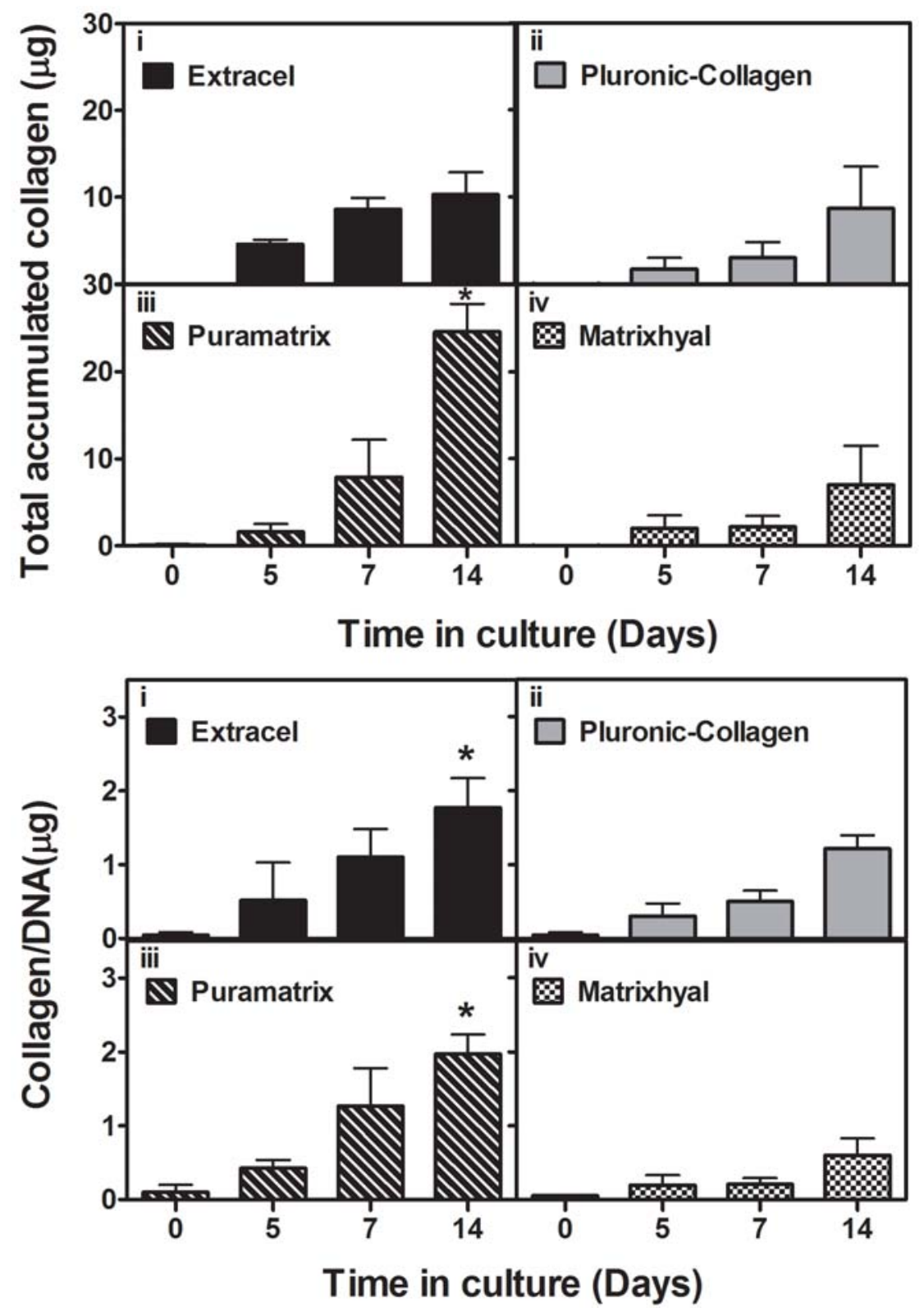

Fig.3 (A) Total collagen accumulated within the four hydrogel formulations. (B) For each hydrogel, the total collagen accumulated $(n=4)$ was normalised to the DNA content. Asterisk indicates significant $\left({ }^{*} p<0.05\right)$ increase in collagen production vs. all other hydrogels at the same time point. 

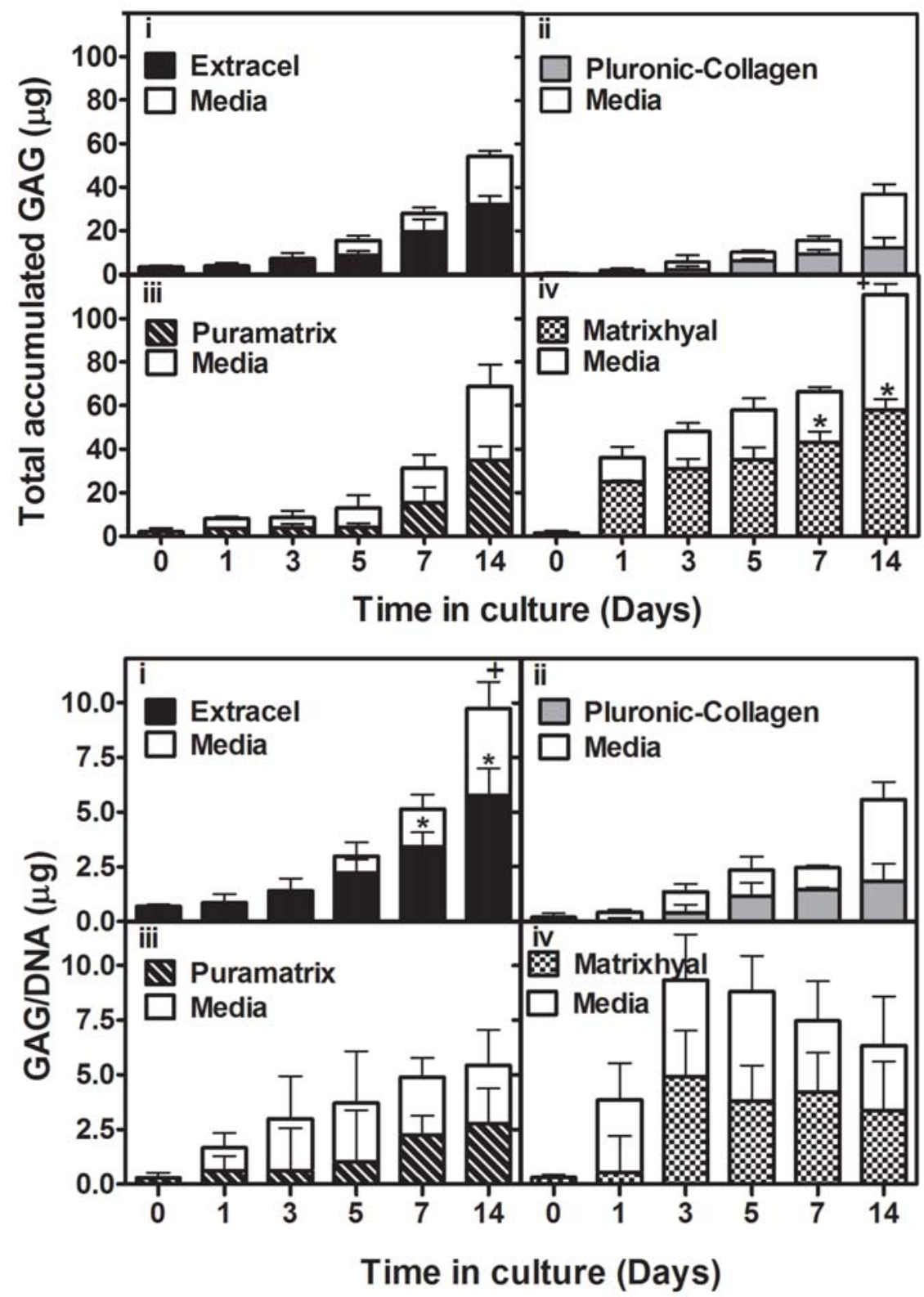

Fig.4 (A) Total sulphated glycosaminoglycan accumulated within the four hydrogel formulations and the media. (B) For each hydrogel and media, the total GAG accumulated $(n=4)$ were normalised to the DNA content. Asterisk indicates significant $(* p<0.05)$ increase in $\mathrm{GAG}$ production vs all other hydrogels at the same time point. Plus sign indicates significant $(+p<0.001)$ loss of GAGs to media vs. some other hydrogels at the same time point.

three hydrogels (Fig. 4B, $p<0.05$ for days in culture). None of the hydrogels retained all of the GAGs during the time course. At day 7 there was no significant difference with respect to GAG/DNA loss to the media. At day 14 Extracel ${ }^{\circledR}$ lost significantly more GAG/DNA to the surrounding media than Puramatrix ${ }^{\circledR}(3.8 \pm 0.52 \mu \mathrm{g} v$. $1.5 \pm 0.52 \mu \mathrm{g} ; p<0.01)$.

\section{HA and CS profiling by FACE}

Fig. 5 is a representative FACE gel showing the coelectrophoresis of a known concentration of pre-defined fluorotagged saccharide standards alongside hyaluronidase and cABC digestion products obtained from Puramatrix ${ }^{\circledR}$ (Fig. 5). Two image exposures were captured. The first exposure (Fig.5A) was used for quantitation as it had all of the pixels within a linear 12-bit depth range to provide baseline data. The second exposure (Fig. 5B) had an oversaturated pixel intensity allowing identification of less abundant structures. Lane 1 is the negative control. Lane 2 shows HA disaccharides ( $\triangle \mathrm{DiHA})$ after hyaluronidase digestion. Lane 3 shows the CS disaccharides $(\triangle \mathrm{Di} 0 \mathrm{~S}$, $\triangle \mathrm{Di} 4 \mathrm{~S}$ and $\triangle \mathrm{Di} 6 \mathrm{~S})$ after $\mathrm{cABC}$ digestion. The $\mathrm{CS}$ disaccharides were digested using chondroitin-4ase (Lane 5) or chondroitin-6ase (Lane 6) to confirm the presence of sulphation.

The FACE data for HA and CS are summarised in Fig. 6. Total CS and HA in the native bovine cartilage preparation were determined to be $22.47 \pm 1.04 \mathrm{pg} / \mathrm{cell}$ and $0.74 \pm 0.34 \mathrm{pg} / \mathrm{cell}$, respectively. The total CS comprised $\Delta \mathrm{Di} 6 \mathrm{~S}(54.74 \%), \Delta \mathrm{Di} 4 \mathrm{~S}(31.39 \%)$, and $\Delta \mathrm{Di} 0 \mathrm{~S}(13.87 \%)$. For Puramatrix ${ }^{\circledR}, \mathrm{CS}$ and HA were determined to be $1.95 \pm 0.26 \mathrm{pg} / \mathrm{cell}$ and $0.18 \pm 0.04 \mathrm{pg} /$ cell, respectively. The total CS comprised $\Delta \mathrm{Di} 6 \mathrm{~S}(45.81 \%), \Delta \mathrm{Di} 4 \mathrm{~S}(35.61 \%)$, and $\triangle \mathrm{DiOS}(18.58 \%)$. For the Pluronic-Collagen, $\mathrm{CS}$ and HA were determined to be $0.52 \pm 0.21 \mathrm{pg} /$ cell and $0.38 \pm 0.15$ $\mathrm{pg} / \mathrm{cell}$, respectively. The total CS comprised $\triangle \mathrm{Di} 6 \mathrm{~S}$ (23.73\%), $\Delta \mathrm{Di} 4 \mathrm{~S}(14.08 \%)$, and $\Delta \mathrm{DiOS}(62.19 \%)$. For Matrixhyal ${ }^{\circledR}, \mathrm{CS}$ and $\mathrm{HA}$ were determined to be $0.34 \pm 0.25$ $\mathrm{pg} / \mathrm{cell}$ and $0.09 \pm 0.02 \mathrm{pg} / \mathrm{cell}$, respectively. The total CS comprised $\Delta \mathrm{Di} 6 \mathrm{~S}(11.49 \%), \Delta \mathrm{Di} 4 \mathrm{~S}(58.00 \%)$, and $\Delta \mathrm{Di} 0 \mathrm{~S}$ $(30.51 \%)$. 


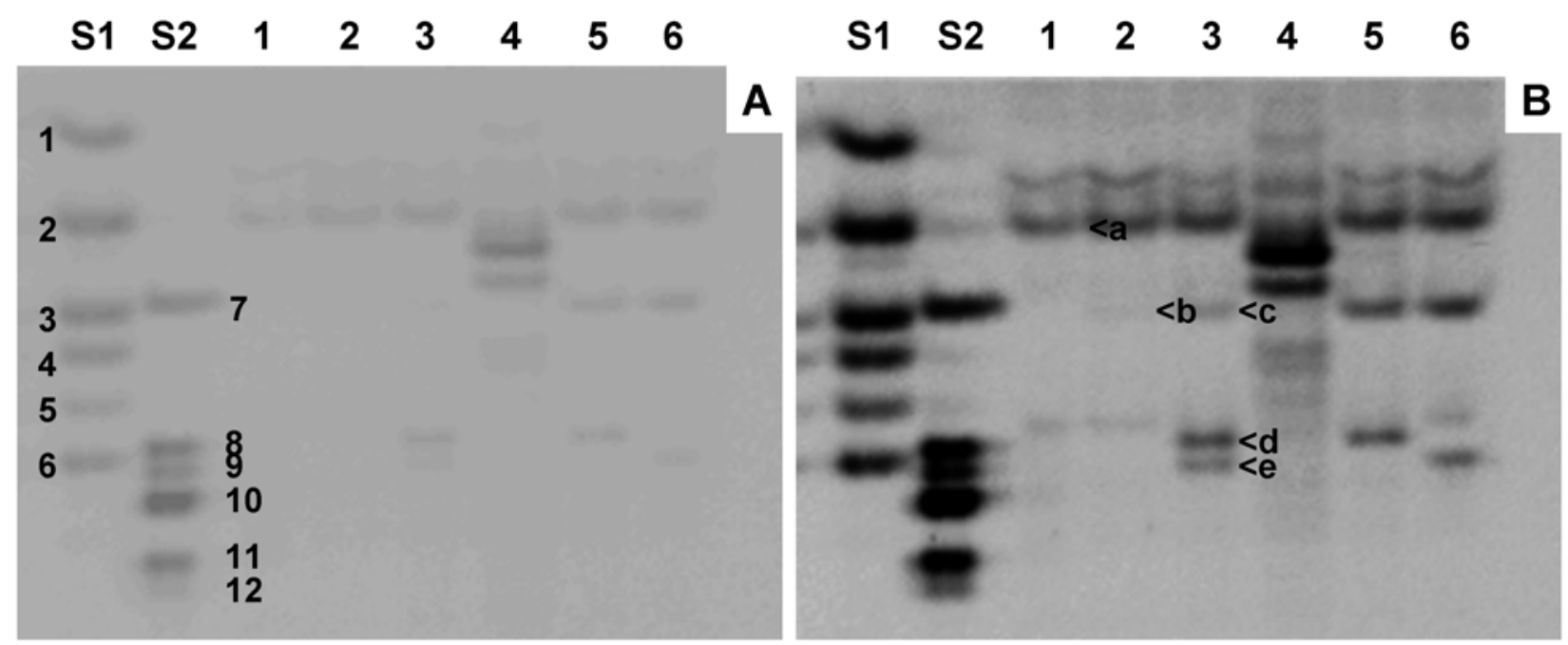

Fig. 5 Representative FACE gel for analysis of HA and CS of the Puramatrix ${ }^{\circledR}$ hydrogel. The first exposure (A) was used for quantitation to provide baseline data. The second exposure (B) had oversaturated pixel intensity to allow identification of less abundant structures. Lanes S1 and S2 contain predefined fluorotagged saccharide standards. S1: Glucose (1), Nacetyl galactosamine (GalNAc) (2), $\Delta$ Di0S (3), Nacetyl galactosamine6 sulphate (GalNAc6S) (4), Nacetyl galactosamine4 sulphate (GalNAc4S) (5) and 4/6sulphated Nacetyl galactosamine $($ GalNAc4,6S) $(6)$. S2: DiHA (7); $\Delta$ Di6S (8), $\Delta$ Di4S (9); dermatan sulphate disaccharides $\Delta$ Di2S (10), $\Delta$ Di4,6S (11) and Di2,6S (12). Samples were digested with Streptococcus dysgalactiae hyaluronidase (lane 2), cABC (lane 3), cABC + mercuric ion treatment (lane 4), cABC + chondroitin4ase (lane 5) and cABC + chondroitin6ase (lane 6). Lane 1 is the negative control. Arrows indicate the migratory position of Glucose (a), $\Delta \mathrm{DiHA}(\mathrm{b}), \Delta \mathrm{Di0S}(\mathrm{c}), \Delta \mathrm{Di} 6 \mathrm{~S}(\mathrm{~d})$, and $\Delta \mathrm{Di} 4 \mathrm{~S}(\mathrm{e})$.

\section{Discussion}

This study was designed to examine the influence of different hydrogels on ECM synthesis over a 2 wk culture period. It is important to understand chondrocyte behaviour and ECM synthesis in different hydrogels since this may provide essential detail to inform future cartilage tissue engineering strategies. So far, few studies have quantitatively compared ECM production in hydrogels formed using different methods and different polymers. We investigated a range of hydrogels formed by temperature change, self-assembly and chemical crosslinking. Our study presents several notable findings pertaining to the influence of the components within four hydrogel formulations on ECM production. We show that cell morphology and viability differ between the hydrogels. We demonstrate that gross biochemical analyses indicate that the hydrogels support ECM formation but detailed biochemical analyses show that the ECM components do not closely match components found in native cartilage.

Pluronic gelation occurred in response to increasing temperature, Puramatrix ${ }^{\circledR}$ gelation occurred via selfassembly, whilst Extracel ${ }$ and Matrixhyal $®$ gelation occurred via different methods of chemical cross-linking. All four of the hydrogels studied supported chondrocyte in vitro culture to different degrees. At day 0 , chondrocytes were distributed homogenously within each hydrogel (data not show). By day 14, clear differences in the morphology of the cells in each hydrogel were noted. Cells cultured in Extracel ${ }^{\circledR}$ were evenly distributed within small islands. Cells cultured in Matrixhyal ${ }^{\circledR}$ formed even larger islands.
Together, these findings suggest that both gels have a loose structure and large pore size. Cells cultured in Puramatrix ${ }^{\circledR}$ were more fibroblastic in appearance than the other three hydrogels. Puramatrix ${ }^{\circledR}$ has been reported to promote cell adhesion and contain large pores (Yamaoka et al., 2006). Thus bovine chondrocytes exposed to this hydrogel would be expected to adhere to the nanofibres as well as migrate through the large pores between the nanofibres. Cells cultured in Pluronic-Collagen were uniformly distributed and appeared rounded in their morphology, but their cell viability decreased from $70 \%$ to $40 \%$ by the end of the 14 day culture period. This decrease in cell viability could be due to one or all of three reasons. Firstly, it may be due to the high concentration (30\%) of Pluronic F127 used in our study. Concentrations at or above $20 \%$ have been shown to result in decreased cell viability (Roberts et al., 2005, Khattak et al., 2005). Secondly, studies have shown (Brunet-Maheu et al., 2009, Roberts et al., 2005) the importance of frequent media replenishment. We replenished the culture media every third day but this may not have been frequent enough to maintain viability. Thirdly, previous work has suggested that some cell types have better viability than other cell types when cultured in Pluronic F127 (Khattak et al., 2005).

Following their encapsulation, the surrounding microenvironment of the hydrogel would directly or indirectly influence the behaviour of the chondrocyte. This would result in the differential expression of ECM components and/or organisation of the surrounding ECM components (Urban, 1994). Hydrogels with a larger porosity would be expected to loose newly synthesised 
GAGs to the surrounding media. In our study, there were significant differences in the production and retention of newly synthesised ECM components within the four hydrogels. Both Extracel ${ }^{\circledR}$ and Puramatrix ${ }^{\circledR}$ had the greatest accumulation of ECM. The raw data showed that chondrocytes cultured in Matrixhyal ${ }^{\circledR}$ produced the most GAG but the large porosity of the gel could not prevent more than half of the GAGs leaching out into the surrounding media. Puramatrix ${ }^{\circledR}$ accumulated the most collagen. It also accumulated a large amount of GAG but it was noted that GAG synthesis within this hydrogel appeared to increase significantly after day 7 . Puramatrix ${ }^{\circledR}$ does not contain any cartilage ECM components but its nanofibrils, water content and pore size are similar to those found in native cartilage (Zhang et al., 1993). These data may suggest that chondrocytes need to be cultured in Puramatrix ${ }^{\circledR}$ for longer that 14 days for the production of ECM. Extracel ${ }^{\circledR}$ contained significantly more collagen/ DNA and GAG/DNA than all of the other gels. Extracel ${ }^{\circledR}$ comprises modified HA and gelatin, both of which have previously been shown to increase the chondrogenic potential of chondrocytes (Goodstone et al., 2004; Petterson et al., 2009). Both Extracel ${ }^{\circledR}$ and Puramatrix ${ }^{\circledR}$ facilitated ECM synthesis whilst preserving the high cell viability and low cell proliferation. Pluronic-Collagen accumulated very little GAG and collagen.

This study revealed considerable quantitative differences in the disaccharide composition of the accumulated GAGs. FACE detected and quantitated saccharides derived from GAGs in the picomolar range. Of the three hydrogels assessed by FACE, only Puramatrix ${ }^{\circledR}$ had a disaccharide profile which closely matched the disaccharide profile for native articular cartilage (Fig.6). Puramatrix ${ }^{\circledR}$ accumulated significantly more $\Delta \mathrm{Di} 6 \mathrm{~S}$ and $\triangle \mathrm{Di} 4 \mathrm{~S}$ disaccharides than Matrixhyal ${ }^{\circledR}$ or Pluronic-Collagen $(* * p<0.001)$. In terms of CS, there are some similarities between Puramatrix ${ }^{\circledR}$ and native bovine cartilage. The $\Delta$ Di6S: $\triangle$ Di4S ratio for Puramatrix ${ }^{\circledR}$ was determined to be $1.28 \pm 0.11$ which is similar to the ratio found in the native bovine cartilage (Lammi et al., 2004). During adulthood, chondrocytes produce CS chains with more C6S than C4S (Plaas et al., 2001). The functional implication of increased CS6 in adult native cartilage is unclear. There is indirect evidence that it may alter the binding of nutrients (Nakatani et al., 2007) and growth factors (Asada et al., 2009). This could have a downstream effect on chondrocyte migration and chondrogenic potential. Pluronic-Collagen and Puramatrix ${ }^{\circledR}$ had significantly more $\triangle \mathrm{DiHA}$ and $\triangle \mathrm{Di} 0 \mathrm{~S}$ disaccharides than Matrixhyal ${ }^{\circledR}(p<0.05)$. High concentrations of HA are generally found during adulthood and development (Holmes et al., 1990). Our results suggest that Puramatrix ${ }^{\circledR}$ provided a suitable environment in which chondrocytes could produce more relevant levels of specific GAGs. This work has shown that the 3D scaffold microenvironment clearly influences the behaviour of the chondrocyte. It also highlights the importance of closely monitoring ECM production in different scaffolds.
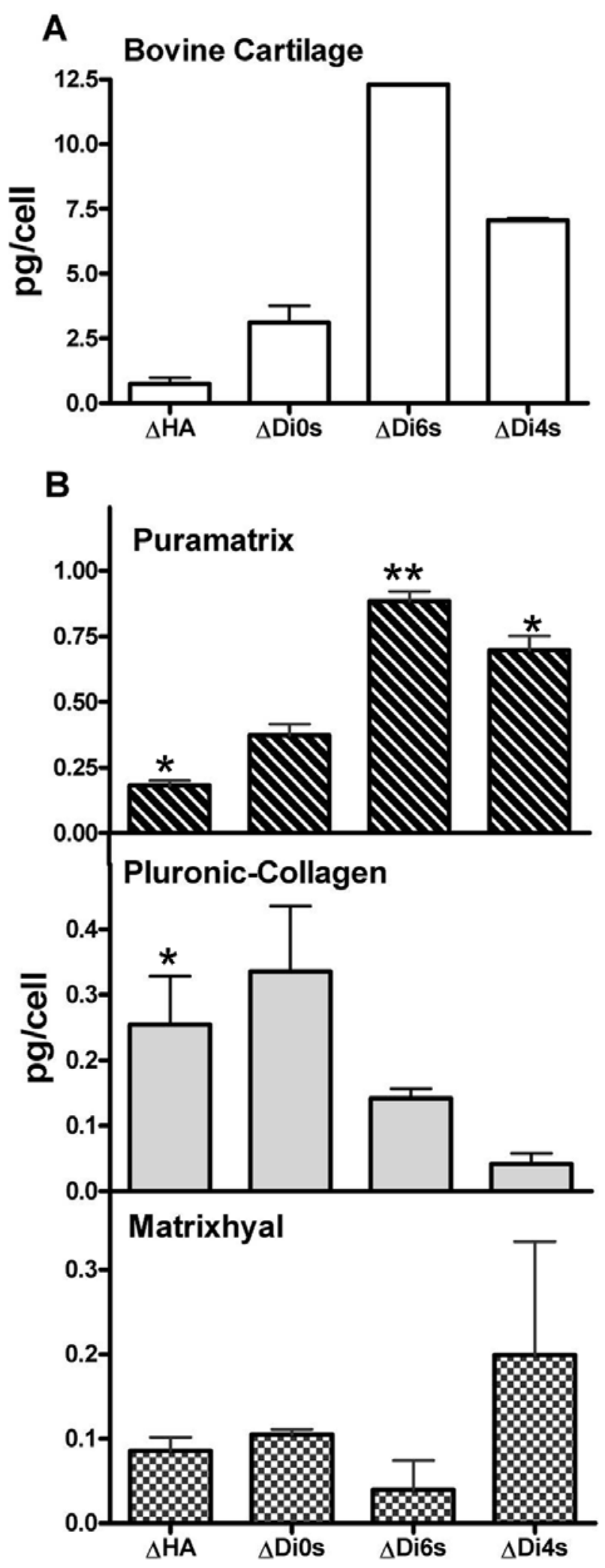

Fig.6 Summary of FACE data for HA and CS. The concentrations of the HA and CS disaccharides derived from Puramatrix ${ }^{\circledR}$, PluronicCollagen and Matrixhyal ${ }^{\circledR}$ as assessed by FACE. Values for native articular cartilage are included for comparison. Values are plotted as pg/ cell. Each bar represents the mean \pm SEM $(n=4)$. Asterisks indicate significant $(* p<0.05, * * p<0.001)$ increases in disaccharide concentration vs. all other hydrogels. 


\section{Acknowledgements}

We would like to acknowledge the RK Memorial Funding for financial support. We also acknowledge the kind gifts of Extracel ${ }^{\circledR}$ from Glycosan Biosystems Inc., Utah and Matrixhyal ${ }^{\circledR}$ from Hyaltech Ltd., Edinburgh.

\section{References}

Asada M, Shinomiya M, Suzuki M, Honda E, Sugimoto R, Ikekita M, Imamura T (2009) Glycosaminoglycan affinity of the complete fibroblast growth factor family. Biochim Biophys Acta 1790: 40-48.

Bayliss MT, Osborne D, Woodhouse S, Davidson C (1999) Sulfation of chondroitin sulphate in human articular cartilage. The effect of age, topographical position and zone of cartilage on tissue composition. J Biol Chem 274: 15892-15900.

Bayliss MT, Howat S, Davidson C, Dudhia J (2000) The organization of aggrecan in human articular cartilage. Evidence for age-related changes in the rate of aggregation of newly synthesized molecules. J Biol Chem 275: 63216327.

Benjamini Y, Liu W (1999) A step-down multiple hypotheses testing procedure that controls the false discovery rate under independence. J Statist Planning Infer 82: $163-170$.

Brown S, Worsfold M, Sharp C (2001) Microplate assay for the measurement of hydroxyproline in acidhydrolyzed tissue samples. Biotechniques 30: 38-40.

Brunet-Maheu JM, Fernandes JC, de Lacerda CA, Shi Q, Benderdour M, Lavigne P (2009) Pluronic F-127 as a cell carrier for bone tissue engineering. J Biomater Appl 24: 275-87.

Buckwalter JA, Roughley PJ, Rosenberg LC (1994) Age-related changes in cartilage proteoglycans: quantitative electron microscopic studies. Microsc Res Tech 28: 398-408.

Buckwalter JA, Mankin HJ (1998) Articular cartilage: tissue design and chondrocyte-matrix interactions. Instr Course Lect 47: 477-86.

Cortivo R, Pagano F, Passerini G, Abatangelo G, Castellani I (1981) Elastin and collagen in the normal and obstructed urinary bladder. Br J Urol 53: 134-137

Farndale RW, Buttle DJ, Barrett AJ (1986) Improved quantitation and discrimination of sulphated glycosaminoglycans by use of dimethylmethylene blue. Biochim Biophys Acta 883: 173-177.

Goodstone NJ, Cartwright A, Ashton B (2004) Effects of high molecular weight hyaluronan on chondrocytes cultured within a resorbable gelatin sponge. Tissue Eng 10: 621-631.

Holmes MW, Bayliss MT, Muir H (1990) Hyaluronic acid in human articular cartilage. Age-related changes in content and size. Biochem J 250: 435-441.

Khattak SF, Bhatia SR, Roberts SC (2005) Pluronic F127 as a cell encapsulation material: utilization of membrane-stabilizing agents. Tissue Eng 11: 974-983.

Kim YJ, Sah RL, Doong JY, Grodzinsky AJ (1988) Fluorometric assay of DNA in cartilage explants using Hoechst 33258 Anal Biochem 174: 168-176.
Lammi MJ, Qu CJ, Laasanen MS, Saarakkala S, Rieppo J, Jurvelin JS, Töyräs J (2004) Undersulfated chondroitin sulfate does not increase in osteoarthritic cartilage. J Rheumatol 31: 2449-2453.

Lauder RM, Huckerby TN, Nieduszynski IA, Plaas AH (1998) Age-related changes in the structure of the keratan sulphate chains attached to fibromodulin isolated from articular cartilage. Biochem J 330: 753-757.

Lee H, Park TG (2009) Photo-crosslinkable, biomimetic, and thermo-sensitive pluronic grafted hyaluronic acid copolymers for injectable delivery of chondrocytes. J Biomed Mater Res A. 88: 797-806.

Liu Y, Shu XZ, Prestwich GD (2006) Osteochondral defect repair with autologous bone marrow-derived mesenchymal stem cells in an injectable, in situ, crosslinked synthetic extracellular matrix. Tissue Eng 12: $3405-$ 3416.

Monroy A, Kojima K, Ghanem MA, Paz AC, Kamil S, Vacanti CA, Eavey RD (2007) Tissue engineered cartilage "bioshell" protective layer for subcutaneous implants. Int J Pediatr Otorhinolaryngol 71: 547-552.

Mouw JK, Case ND, Guldberg RE, Plaas AHK, Levenston ME (2005) Variations in matrix composition and GAG fine structure among scaffolds for cartilage tissue engineering. Osteoarthritis Cartilage 13: 828-836.

Nakatani S, Mano H, Im R, Shimizu J, Wada M (2007) Glucosamine regulates differentiation of a chondrogenic cell line, ATDC5. Biol Pharm Bull 30: 433-438.

Passaretti D, Silverman RP, Huang W, Kirchhoff CH, Ashiku S, Randolph MA, Yaremchuk MJ (2001) Cultured chondrocytes produce injectable tissue-engineered cartilage in hydrogel polymer. Tissue Eng 7: 805-815.

Petterson S, Wetterö J, Tengvall P, Kratz G (2009) Human articular chondrocytes on macroporous gelatin microcarriers form structurally stable constructs with blood-derived biological glues in vitro. J Tissue Eng Regen Med 6: 450-60.

Plaas AH, West L, Midura RJ, Hascall VC (2001) Disaccharide composition of hyaluronan and chondroitin/ dermatan sulfate. Analysis with fluorophore-assisted carbohydrate electrophoresis. Methods Mol Biol 171:11712.

Prabhakar V, Sasisekharan R (2006) The biosynthesis and catabolism of galactosaminoglycans. Adv Pharmacol 53: 69-115.

Prestwich GD (2008). Engineering a clinically-useful matrix for cell therapy. Organogenesis 4: 42-47.

Roberts A, Wyslouzil BE, Bonassar L (2005) Aerosol delivery of mammalian cells for tissue engineering. Biotechnol Bioeng 91:801-807.

Saim AB, Cao Y, Weng Y, Chang CN, Vacanti MA, Vacanti CA, Eavey RD (2006) Engineering autogenous cartilage in the shape of a helix using an injectable hydrogel scaffold. Laryngoscope 10:1694-1697.

Sharma A, Wood LD, Richardson JB, Roberts S, Kuiper NJ (2007) Glycosaminoglycan profiles of repair tissue formed following autologous chondrocyte implantation differ from control cartilage. Arthritis Res Ther 9: R79.

Urban JP (1994) The chondrocyte: a cell under pressure. Br J Rheumatol 33: 901-908. 
Van Tomme SR, Storm G, Hennink WE (2008) In situ gelling hydrogels for pharmaceutical and biomedical applications International Journal of Pharmaceutics 355: $1-18$

Vinatier C, Guicheux J, Daculsi G, Layrolle P, Weiss P (2006) Cartilage and bone tissue engineering using hydrogels. Biomed Mater Eng 16: S107-113.

Wang QG, El Haj AJ, Kuiper NJ (2008) Glycosaminoglycans in the pericellular matrix of chondrons and chondrocytes. J Anat 213: 266-273.

Yamaoka H, Asato H, Ogasawara T, Nishizawa S, Takahashi T, Nakatsuka T, Koshima I, Nakamura K, Kawaguchi H, Chung UI, Takato T, Hoshi K (2006) Cartilage tissue engineering using human auricular chondrocytes embedded in different hydrogel materials. J Biomed Mater Res A 78: 1-11.

Yoshida S, Yamada K, Hamaguchi K (1998) Immunohistochemical study of human advanced glycation end-products (AGE) and growth factors in cardiac tissues of patients on maintenance dialysis and with kidney transplantation. Clin Nephrol 49: 273-280.

Zhang S, Holmes T, Lockshin C, Rich A (1993) Spontaneous assembly of a self-complementary oligopeptide to form a stable macroscopic membrane. Proc Natl Acad Sci 90: 3334-3338.

Zheng Y, Lv H, Wang Y, Lu H, Qing L, Xi T (2009) Performance of novel bioactive hybrid hydrogels in vitro and in vivo used for artificial cartilage. Biomed Mater 4: 15015.

\section{Discussion with Reviewer}

Reviewer II: What do the authors believe is more important, a disaccharide profile similar to native cartilage or the total amount of GAG produced?

Authors: We believe that both are equally important. GAGs have important biological functions such as tissue hydration. The functions of cartilage with little or no GAGs will be drastically compromised so it is crucial that we achieve high GAG levels in the hydrogel. GAG fine structure varies throughout native cartilage. We know that GAGs form a gradient in specific areas of the cartilage allowing cell signalling and cell migration to occur. 